\title{
A quadruple-enterotoxin-deficient mutant of Bacillus thuringiensis remains insecticidal
}

Correspondence

Jo Handelsman

jo.handelsman@yale.edu

Received 19 March 2010

Revised 2 September 2010

Accepted 7 September 2010

\author{
Amy K. Klimowicz, ${ }^{1}$ Terry A. Benson ${ }^{2}$ and Jo Handelsman ${ }^{1} \dagger$ \\ ${ }^{1}$ Departments of Bacteriology and Plant Pathology, University of Wisconsin-Madison, \\ 1550 Linden Dr., Madison, WI, USA \\ ${ }^{2}$ Valent BioSciences Corporation, Agricultural Research Station, 6131 RFD Oakwood Road, \\ Long Grove, IL, USA
}

Bacillus thuringiensis is the leading biopesticide used to control insect pests worldwide. Although they have a long record of safe use, under certain conditions commercial strains of $B$. thuringiensis have the ability to produce numerous putative enterotoxins that have been associated with food poisoning attributed to Bacillus cereus. Therefore, we designed a strategy to delete the genes encoding these toxins. B. thuringiensis strain VBTS 2477 contained genes encoding NHE, CytK-2 and three homologues of haemolysin $\mathrm{BL}\left(\mathrm{HBL}, \mathrm{HBL}_{\mathrm{a} 1}\right.$ and $\left.\mathrm{HBL}_{\mathrm{a} 2}\right)$. This is the first report, to our knowledge, of a strain of $B$. cereus or $B$. thuringiensis containing three sets of $h b /$ operons. The genes encoding $\mathrm{HBL}_{\mathrm{a}_{1}}$ and $\mathrm{HBL}_{\mathrm{a} 2}$ were $96-97 \%$ identical to each other and $76-84 \%$ identical to those encoding HBL. The $h b l_{a 2}$ operon was detected by PCR amplification only after $h b l_{a 1}$ was deleted. We used sequential gene replacement to replace the wild-type copies of the NHE and three HBL operons with copies that contained internal deletions that span the three genes in each operon. The insecticidal activity of the quadruple-enterotoxin-deficient mutant was similar to that of the wild-type strain against larvae of Trichoplusia ni, Spodoptera exigua and Plutella xylostella. This demonstrates that the genes for enterotoxins can be deleted, eliminating the possibility of enterotoxin production without compromising the insecticidal efficacy of a strain of $B$. thuringiensis.

\section{INTRODUCTION}

Bacillus thuringiensis has been used globally for over 50 years as a bioinsecticide for the control of insect pests in agriculture, forestry and public health. B. thuringiensis produces one or more crystal proteins during sporulation that are toxic to insect larvae upon ingestion. The toxins exhibit a narrow host spectrum, with an individual toxin typically affecting a subset of species within an insect order (Lepidoptera, Diptera, Coleoptera). Numerous studies show B. thuringiensis to be harmless to humans and mammals (Fisher \& Rosner, 1959; US Environmental Protection Agency, 1998) and it has become increasingly popular as a

tPresent address: Department of Molecular, Cellular and Developmental Biology, Yale University, New Haven, CT 06520, USA.

Abbreviations: BCET-RPLA, Bacillus cereus enterotoxin-reverse passive latex agglutination; BDE, Bacillus diarrhoeal enterotoxin; LC $50,50 \%$ lethal concentration; SOE, gene splicing by overlap extension.

The GenBank/EMBL/DDBJ accession numbers for the near-full-length enterotoxin operon sequences of $B$. thuringiensis are EU925141EU925144.

A supplementary table, listing the primers used for detection of enterotoxin genes and generation of deletion constructs by SOEing $\mathrm{PCR}$, is available with the online version of this paper. method of insect control that is more environmentally friendly than synthetic chemical insecticides.

B. thuringiensis is a Gram-positive spore-forming bacterium that is a member of the Bacillus cereus group. Phylogenetic studies and whole-genome sequencing reveal that $B$. thuringiensis and $B$. cereus are members of the same species group (Carlson et al., 1994; Helgason et al., 2000; Hill et al., 2004; Rasko et al., 2005). Both B. thuringiensis and B. cereus are found in soils, in the guts of invertebrates and associated with plants (Smith \& Couche, 1991; Margulis et al., 1998; Martin \& Travers, 1989; Jensen et al., 2003; Jara et al., 2006; Swiecicka \& Mahillon, 2006; Bizzarri \& Bishop, 2007), and the only distinguishing phenotype is the production in $B$. thuringiensis of plasmid-encoded crystal toxins upon sporulation. Some strains of B. cereus are known to be foodpoisoning agents and opportunistic pathogens (Kotiranta et al., 2000). Pathogenic strains of B. cereus are responsible for two foodborne illnesses: an emetic syndrome, caused by a small cyclic peptide cereulide (Agata et al., 1995), and a diarrhoeal syndrome, caused by one or more putative enterotoxins (Beecher \& MacMillan, 1991; Lund \& Granum, 1996; Granum et al., 1999; Lund et al., 2000).

Many commercial strains of $B$. thuringiensis carry the genes encoding putative diarrhoeal enterotoxins. This has generated 
debate in the scientific community about whether $B$. thuringiensis on produce could cause food poisoning (Damgaard, 1995; Hansen \& Hendriksen, 2001; Frederiksen et al., 2006, Rosenquist et al., 2005; Kyei-Poku et al., 2007). Early toxicology studies of $B$. thuringiensis included tests on human volunteers who ingested $1 \mathrm{~g}\left(3 \times 10^{9}\right.$ B. thuringiensis spores) of the commercial product Thuricide daily for 5 days without any adverse health effects (Fisher and Rosner, 1959). More recently, greenhouse workers exposed to $B$. thuringiensis-based sprays were found to carry $10^{2}-10^{3}$ c.f.u. $B$. thuringiensis $\mathrm{g}^{-1}$ in faecal samples but the presence of $B$. thuringiensis did not correlate with any gastrointestinal symptoms (Jensen et al., 2002), suggesting that it was unlikely that $B$. thuringiensis exposure would be implicated in human illness. However, food poisoning outbreaks caused by a $B$. thuringiensis strain could be mistakenly attributed to B. cereus, since clinical laboratories have not routinely examined putative B. cereus isolates for the presence of crystal toxins. Moreover, heat treatment of food can result in plasmid loss, and therefore a $B$. thuringiensis strain that caused disease would no longer carry $B$. thuringiensis-specific genes at the time of diagnosis (Granum, 2002; European Food Safety Authority, 2005). A recent report re-examined 155 B. cereusgroup-like species collected from 39 foodborne outbreaks in British Columbia, Canada, between 1991 and 2005 (McIntyre et al., 2008). Of these B. thuringiensis isolates, 23 were identified as the only Bacillus sp. associated with four of the outbreaks for which B. cereus was originally reported. Due to the concern about food safety, some scientists have advocated deleting the genes for the enterotoxins from commercial strains (Damgaard, 1995; Gaviria Rivera et al., 2000). Others have suggested that the use of $B$. thuringiensis is unlikely to pose a public health risk but that removal of the enterotoxin genes would be a prudent precaution that would allay public concerns (Kyei-Poku et al., 2007).

In this study, we examined a strain of B. thuringiensis for the presence of genes encoding three enterotoxins that have been implicated in diarrhoeal illness: three-component enterotoxin complexes haemolysin BL (HBL) and NHE and cytotoxin K (CytK) (Beecher \& MacMillan, 1991; Lund \& Granum, 1996; Lund et al., 2000; reviewed by Stenfors Arnesen et al., 2008). HBL has haemolytic, vascular permeability and dermonecrotic activities, is cytotoxic and causes fluid accumulation in the rabbit ileal loop (RIL) assay (Beecher \& MacMillan, 1991; Beecher \& Wong, 1994b; Beecher et al., 1995; Lund \& Granum, 1997), considered the definitive assay for diarrhoeal toxins (Bergdoll, 1988). The enterotoxigenicity of NHE and CytK are inferred from their cytotoxicity toward different cell lines, including human intestinal Caco-2 cells, and their ability to form pores in planar lipid bilayers (Hardy et al., 2001; Lindbäck et al., 2004; Fagerlund et al., 2008).

HBL and NHE are each comprised of three proteins encoded by genes that are arranged in operons (Heinrichs et al., 1993; Ryan et al., 1997; Granum et al., 1999). The respective HBL and NHE proteins share $23-40 \%$ sequence identity and they may be part of a family of pore-forming toxins (Fagerlund et al., 2008). A homologue of HBL, $\mathrm{HBL}_{\mathrm{a}}$, was isolated from a strain of $B$. cereus that produces two distinct sets of HBL proteins (Beecher \& Wong, 2000). The $\mathrm{HBL}_{\mathrm{a}}$ set exhibited biological activity similar to the prototypic HBL set, and the homologous proteins functioned interchangeably, suggesting that $\mathrm{HBL}_{\mathrm{a}}$ may also contribute to food poisoning.

Cytotoxin $\mathrm{K}$ is a single-protein enterotoxin that was originally isolated from a strain of $B$. cereus that caused a food poisoning outbreak that resulted in three fatalities (Lund et al., 2000). Two versions have been characterized: the original version, CytK-1, which appears to be limited to a genetically remote cluster of $B$. cereus strains (Fagerlund et al., 2007) and a second version, CytK-2, which exhibits lower toxicity toward human intestinal epithelial cells (Fagerlund et al., 2004). It is not known whether CytK-2 contributes to the diarrhoeal illness.

In this study we screened a strain of B. thuringiensis subsp. kurstaki for the presence of genes that encode $\mathrm{HBL}, \mathrm{HBL}_{\mathrm{a}}$, NHE and CytK. We performed a series of gene replacements, in which we replaced four enterotoxin operons with copies that contain large deletions, and assessed the activity of the quadruple mutant in insect bioassays.

\section{METHODS}

Bacterial strains, plasmids and growth conditions. The strains and plasmids used in the present study are listed in Table 1. Escherichia coli was grown in Luria-Bertani (LB) medium at $37{ }^{\circ} \mathrm{C}$. B. thuringiensis was grown in either LB or half-strength tryptic soy broth (TSB) or on half-strength tryptic soy agar (TSA) at 28,37 or $40.5{ }^{\circ} \mathrm{C}$. For conjugation, B. thuringiensis was grown in brain heart infusion (BHI) medium. Antibiotics were used at the following concentrations: for E. coli, $200 \mu \mathrm{g}$ ampicillin $\mathrm{ml}^{-1} ; 10 \mu \mathrm{g}$ chloramphenicol $\mathrm{ml}^{-1}$; for B. thuringiensis, $3 \mu \mathrm{g}$ erythromycin $\mathrm{ml}^{-1}$ for selection of $\mathrm{pMAD}$ or $5 \mu \mathrm{g}$ erythromycin $\mathrm{ml}^{-1}$ for selection of $\mathrm{pBKJ} 236 ; 60 \mu \mathrm{g}$ polymixin $\mathrm{B}$ $\mathrm{ml}^{-1}$ for conjugations with $\mathrm{pBKJ} 236$ and10 $\mu \mathrm{g}$ tetracycline $\mathrm{ml}^{-1}$ for selection of pBKJ223.

DNA isolation. Genomic DNA was isolated from cultures of $B$. thuringiensis that were grown with shaking overnight. DNA was isolated either by the boiling-cell-lysis method (Raffel et al., 1996) or by Protocol no. 3 in the Easy-DNA kit (Invitrogen), except that prior to the addition of solution $\mathrm{A}$, the cells were pelleted, resuspended in sterile water and vortexed for 2-3 min with $50 \mu \mathrm{ll} 0.1 \mathrm{~mm}$ diameter silica beads to enhance cell lysis. Plasmid DNA was isolated from $E$. coli using the Qiagen Spin Miniprep kit (Qiagen).

Transformation and conjugation. Competent cells of $E$. coli were electroporated in $0.2 \mathrm{~cm}$ cuvettes with a Gene Pulser apparatus (BioRad Laboratories) set at $2.5 \mathrm{kV}, 200 \Omega$ and $25 \mu \mathrm{F}$. Cells were transferred to $1 \mathrm{ml} \mathrm{LB}$, allowed to recover for $1 \mathrm{~h}$ at $37{ }^{\circ} \mathrm{C}$ with shaking and then plated on selective media. Competent cells of $B$. thuringiensis were prepared as described previously (Silo-Suh et al., 1994) or by the method described by Janes \& Stibitz (2006). Because B. thuringiensis restricts methylated DNA, recombinant plasmids isolated from E. coli DH5 $\alpha$ were passed through E. coli GM2929 (methylation-deficient strain) before being introduced into $B$. thuringiensis. pBKJ236:: $\Delta h b l_{a 2}$ was introduced into the $B$. thuringiensis triple mutant by conjugation as described by Janes \& Stibitz (2006). 
Table 1. Bacterial strains and plasmids used in this study

\begin{tabular}{|c|c|c|}
\hline Strain or plasmid & Description & Source or reference \\
\hline \multicolumn{3}{|l|}{ B. thuringiensis } \\
\hline VBTS 2477 & B. thuringiensis subsp. kurstaki wild-type strain; cry1Aa cry $1 A b$ cry $1 A c$ cry $2 A a$ cry $2 A b$ & Valent Biosciences \\
\hline AK7702 & VBTS $2477 \Delta h b l_{a 1} \Delta n h e$, double mutant & This study \\
\hline AK7703 & VBTS $2477 \Delta h b l_{a 1} \Delta$ nhe $\Delta h b l$, triple mutant & This study \\
\hline AK7704 & VBTS $2477 \Delta h b l_{a 1} \Delta n h e \Delta h b l \Delta h b l_{a 2}$, quadruple mutant & This study \\
\hline DH5 $\alpha$ & General purpose strain & Hanahan (1983) \\
\hline GM2929 & dcm-6 dam-13:: Tn9, $\mathrm{Cm}^{\mathrm{r}}$ & E. coli Genetic Stock Center \\
\hline SS1827 & Helper strain for conjugation into B. thuringiensis, $\mathrm{Amp}^{\mathrm{r}}$ & Janes \& Stibitz (2006) \\
\hline \multicolumn{3}{|l|}{ Plasmids } \\
\hline pMAD & Temperature-sensitive gene replacement vector, Ery ${ }^{\mathrm{r}}$, expresses $\beta$-galactosidase gene & Arnaud et al. (2004) \\
\hline pBKJ236 & $\begin{array}{l}\text { Temperature-sensitive gene replacement vector, Ery }{ }^{\mathrm{r}} \text {, contains } 18 \text { bp recognition } \\
\text { site for I-SceI }\end{array}$ & Janes \& Stibitz (2006) \\
\hline
\end{tabular}

Screening for presence of enterotoxin genes. Gene sequences for HBL ( $h b l C, h b l D, h b l A)$, NHE (nheA, nheB, nheC) and $c y t K$ were obtained from strains of $B$. cereus and $B$. thuringiensis that were available in the GenBank database at the onset of this study, and from the unpublished B. cereus UW85 partial genome sequence (D. Rasko, J. Ravel, J. Handelsman, unpublished data). Sequences were aligned using the DNASTAR program MEGALIGN and regions of high conservation were selected for PCR primer sequences (see Supplementary Table S1, available with the online version of this paper). Primers for $c y t K$ were designed to amplify either variant of the gene $(c y t K-1$ or $c y t K-2)$. The $\mathrm{HBL}_{\mathrm{a}}$ primers were based on the UW85 genome and differed from the corresponding HBL region by 2-6 nt. Primers were synthesized at Integrated DNA Technologies. Typical PCRs contained $1 \mu \mathrm{l}$ genomic DNA, $2 \mu \mathrm{l} 10 \times$ Taq buffer, $0.5 \mu \mathrm{M}$ of each primer, $0.2 \mathrm{mM}$ of each dNTP, $0.2 \mu \mathrm{l}$ Taq DNA polymerase (Promega) in a final volume of $20 \mu \mathrm{l}$. PCR cycle conditions consisted of an initial 1 min denaturation at $94{ }^{\circ} \mathrm{C}$, followed by 35 cycles of $30 \mathrm{~s}$ at $94{ }^{\circ} \mathrm{C}, 1.5 \mathrm{~min}$ at $55^{\circ} \mathrm{C}, 2 \mathrm{~min}$ at $72{ }^{\circ} \mathrm{C}$, and a final extension of $5 \mathrm{~min}$ at $72{ }^{\circ} \mathrm{C}$. PCR products were analysed on $0.8 \%$ agarose gels.

Sequence analysis of enterotoxin operons in VBTS 2477. To obtain near-full-length sequences of the $h b l, h b l_{a 1}$ and nhe enterotoxin operons in VBTS 2477, primers to the ends of each operon were used to amplify each one (i.e. hblC-F/hblA-R; hblCa-F/hblAa-R, nheA-F/ nheC-R), the products were purified using AMPure magnetic beads (Agencourt Bioscience), and the full sequence was obtained by primer walking. For $h b l_{a 2}$, sequence was obtained from the PCR products generated with the following primer pairs using genomic DNA from the $\Delta h b l_{a 1}$ mutant: hblCa-F/hblDa-R, and hblDa-F/hblAa-R. Typical sequencing reactions consisted of $1 \mu \mathrm{l}$ BigDye Terminator v. $3.1 \mathrm{mix}$ (Applied Biosystems), $1.5 \mu \mathrm{l}$ sequencing buffer v. 3.1 (Applied Biosystems), $0.5 \mu \mathrm{M}$ of each primer and $5 \mu \mathrm{l}$ template DNA in a final reaction volume of $20 \mu \mathrm{l}$. Cycle conditions were an initial $3 \mathrm{~min}$ denaturation at $95{ }^{\circ} \mathrm{C}$, followed by 35 cycles of $10 \mathrm{~s}$ at $96{ }^{\circ} \mathrm{C}, 3.5 \mathrm{~min}$ at $58{ }^{\circ} \mathrm{C}$, and a final extension of $7 \mathrm{~min}$ at $72{ }^{\circ} \mathrm{C}$. Excess dye terminators were removed using the CleanSeq magnetic bead sequencing reaction clean up kit (Agencourt Bioscience). Sequencing gels were run on an Applied Biosystems 3730xl automated DNA sequencing instrument at the University of Wisconsin Biotechnology Center. Data were analysed using PE-Biosystems version 3.7 of Sequencing Analysis. Contigs were assembled using the DNASTAR software SeqMan. Nucleotide sequences of the near-full-length enterotoxin operons were deposited in GenBank under the accession numbers EU925141-EU925144.
Generation of deletion constructs by gene splicing by overlap extension (SOE)ing PCR. The deletion constructs were created by SOEing PCR (Horton et al., 1989). The SOEing primers used in this study are presented in Supplementary Table S1. To generate the $\Delta h b l_{a 1}$ and $\Delta h b l_{a 2}$ constructs, the same set of outer primers was used (hblCa_Bam-F, hblAa_Bam-R) as the sequences of the two homologues in these regions were identical, but different overlapping primers were selected so that different-sized deletions was introduced. This enabled us to discriminate between the two mutations by PCR.

Typical conditions for the first round of PCRs were $1 \mu$ genomic DNA, $5 \mu \mathrm{l} 10 \times P f u$ buffer, $0.5 \mu \mathrm{M}$ of each primer, $0.4 \mathrm{mM}$ dNTPs and $0.5 \mu \mathrm{l} P \mathrm{fu}$ DNA polymerase (Stratagene) in a total volume of $50 \mu \mathrm{l}$. For the $\Delta h b l_{a 2}$ construct, the template consisted of the PCR fragments obtained with the hblCa-F/hblDa-R and hblDa-F/hblAa-R primer sets used with genomic DNA from the $\Delta h b l_{a 1}$ mutant. PCR cycle conditions were 30 cycles of $30 \mathrm{~s}$ at $94{ }^{\circ} \mathrm{C}, 30 \mathrm{~s}$ at $55{ }^{\circ} \mathrm{C}$ and $1 \mathrm{~min}$ at $72^{\circ} \mathrm{C}$. The PCR fragments were purified using AMPure magnetic beads (Agencourt Biosciences). Reaction conditions for the second round of PCR were the same as for the first round except the template consisted of $0.5 \mu \mathrm{l}$ of the PCR fragments of the $5^{\prime}$ and $3^{\prime}$ regions of the operon, and Taq DNA polymerase (Promega) was used instead of $P f u$. The same PCR program was used for the second round of amplification. The spliced PCR product was gel-purified using the QIAEX II gel purification kit (Qiagen).

The resulting deletion constructs were digested with BamHI (Promega) and ligated to either pMAD $\left(\Delta h b l_{a 1}, \Delta n h e, \Delta h b l\right)$ or pBKJ236 $\left(\Delta h b l_{a 2}\right)$ that had been BamHI-digested and treated with shrimp alkaline phosphatase (Promega). The recombinant vectors were confirmed by restriction digest analysis and the inserts were sequenced.

Gene replacement using pMAD or pBKJ236/pBKJ223. Gene replacement with the pMAD constructs was carried out in a manner similar to the method described by Arnaud et al. (2004). For construction of the first mutant $\left(\Delta h b l_{a 1}\right)$ of the series, pMAD : : $\Delta h b l_{a 1}$ was electroporated into $B$. thuringiensis 2477 and transformants were selected on half-strength TSA with erythromycin $\left(3 \mu \mathrm{g} \mathrm{ml}^{-1}\right)$ and XGal $\left(50 \mu \mathrm{g} \mathrm{ml}^{-1}\right)$ after two days of incubation at $28{ }^{\circ} \mathrm{C}$, the permissive temperature for plasmid replication. The gene replacement was conducted in two steps by first selecting for a single recombination event resulting in integration of the plasmid at the enterotoxin locus, and then screening for excision of the plasmid by a second recombination event and subsequent loss of the plasmid. 
Transformants were grown on plates containing erythromycin at $40.5{ }^{\circ} \mathrm{C}$, the nonpermissive temperature for replication of pMAD, to select for clones in which the plasmid had integrated into the chromosome via a single crossover event. Integrants were then grown at the permissive temperature in nonselective media to allow for a second crossover event, and then diluted into fresh medium and grown at the nonpermissive temperature to cure remaining freely replicating plasmid. Cultures were plated for single colonies on halfstrength TSA with X-Gal at $40.5{ }^{\circ} \mathrm{C}$ and screened for white colonies, which were putative double recombinants. PCR analysis was performed on genomic DNA to determine whether the double recombinants had reverted to wild-type $h b l_{a 1}$ or had undergone a successful gene replacement and to verify the absence of the plasmid. The nhe and $h b l$ operons were replaced with the $\Delta n h e$ and $\Delta h b l$ deletion constructs in an iterative manner to obtain the triple mutant.

We were unable to obtain the quadruple mutant using the pMAD : : $\Delta h b l_{a 2}$ construct due to an unexpected low frequency of recombination in the integrant. Therefore, we used the pBKJ236/ pBKJ223 gene replacement system (Janes \& Stibitz, 2006) which enhances the frequency of the second crossover event. pBKJ236:: $\Delta h b l_{a 2}$ was introduced into the triple mutant by conjugation, and integrants were selected on BHI with erythromycin at $37{ }^{\circ} \mathrm{C}$, the non-permissive temperature for replication. Integration at the $h b l_{a 2}$ locus was verified by PCR analysis $\left(1 \mathrm{~min}\right.$ at $94{ }^{\circ} \mathrm{C}$ followed by 35 cycles of $30 \mathrm{~s}$ at $94{ }^{\circ} \mathrm{C}$, $1.5 \mathrm{~min}$ at $55{ }^{\circ} \mathrm{C}$ and $2 \mathrm{~min}$ at $72{ }^{\circ} \mathrm{C}$, and final extension of $5 \mathrm{~min}$ at $72{ }^{\circ} \mathrm{C}$ ), using one primer specific to the chromosome and one to the vector (hblDa2-F, 5'-GCT GCT AAA CAA AGT TGG AAT G-3', pBKJ236-R, 5'-CGT AAT ACG ACT CAC TAT AGG G-3'). pBKJ223 was electroporated into the integrant and selected on media containing tetracycline. A resulting transformant was grown in half-strength TSB with tetracycline overnight at $28{ }^{\circ} \mathrm{C}$ and plated for single colonies on half-strength TSA with tetracycline and incubated at $37^{\circ} \mathrm{C}$. Colonies were screened for sensitivity to erythromycin to identify putative double recombinants that had lost $\mathrm{pBKJ} 236$ via a second crossover event. The double recombinants were screened by PCR with hblCa_Bam-F/ hblAa_Bam-R primers to identify clones that had retained the $\Delta h b l_{a 2}$ locus. The quadruple mutant was grown in half-strength TSB at $37{ }^{\circ} \mathrm{C}$ and single colonies were patched onto plates with and without tetracycline to identify isolates that had been cured of pBKJ223.

Commercial assays for detection of enterotoxin proteins. Two commercial immunoassay kits were used for the detection of the $\mathrm{L}_{2}$ component of HBL and the NheA protein of NHE. Cultures of $B$. thuringiensis strain VBTS 2477, the single, double, triple and quadruple mutants were grown for $18 \mathrm{~h}$ in $125 \mathrm{ml}$ flasks containing $12 \mathrm{ml} \mathrm{BHI}$ with $0.1 \%$ glucose. The cultures were centrifuged and the supernatant was filter-sterilized through a $0.22 \mu \mathrm{m}$ pore filter (Millipore). The cellfree culture supernatants were then assayed with the Oxoid Bacillus cereus enterotoxin reverse passive latex agglutination (BCET-RPLA) kit (Fisher Scientific) and the Tecra Bacillus diarrhoeal enterotoxin (BDE) visual immunoassay (VIA) (3M) according to the manufacturer's instructions, with the exception that in the Oxoid assay, four additional dilutions were included for each sample. The assays were performed on two independent sets of cultures.

Preparation of fermentation broths. Culture broths were prepared in 7.51 fermenters under proprietary manufacturing conditions for production of $B$. thuringiensis-based pesticides. Media comprised an organic nitrogen source (such as flours, yeast extract, fish meal, etc.) and glucose with typical salts used in fermentation processes. Cultures were grown under aerobic conditions at $28{ }^{\circ} \mathrm{C}$ with agitation until sporulation was complete. The same cultures were used for both bioassays and protein analysis.

Protein analysis of $B$. thuringiensis crystal toxins. Approximately $100 \mathrm{mg}$ of each fermentation broth was transferred into microfuge tubes, weighed and washed in $1 \mathrm{M} \mathrm{NaCl}-5 \mathrm{mM}$ EDTA $\mathrm{pH} 8.0$, then once in $5 \mathrm{mM}$ EDTA $\mathrm{pH} 8.0$, followed by centrifugation at $14000 \mathrm{~g}$ after each wash. The pellets were resuspended in $1 \mathrm{ml} 5 \mathrm{mM}$ EDTA pH 8.0. Aliquots $(100 \mu \mathrm{l})$ were transferred to fresh microfuge tubes and centrifuged as before. The pellets were resuspended in $150 \mu \mathrm{l}$ sample buffer $\mathrm{pH} 10.0$ [8 M urea, $0.05 \mathrm{M}$ CAPS, $2 \%$ (w/v) SDS, $20 \mathrm{mM} \mathrm{DTT}$ ], boiled for $8 \mathrm{~min}$, followed by addition of $150 \mu \mathrm{l}$ sample buffer $\mathrm{pH} 8.8$ [0.25 M Tris, $2 \%(\mathrm{w} / \mathrm{v})$ SDS, $40 \%$ (v/v) glycerol, $20 \mathrm{mM} \mathrm{DTT}$. Aliquots of a DiPel technical powder (a proprietary fermentation broth of the DiPel strain, which has been concentrated and spray-dried) quantitative standard were prepared in a similar manner. After a brief centrifugation, $5 \mu \mathrm{l}$ of each sample and standard were loaded onto an $8-16 \%$ Tris-glycine denaturing gel (Novex; Invitrogen). The gel was electrophoresed for approximately $2 \mathrm{~h}$, stained overnight with Colloidal Blue (Invitrogen), and destained to produce a clear background. The gel was scanned using a Bio-Rad GS-710 scanning densitometer. The 135 and $60 \mathrm{kDa}$ bands (Cryl and Cry2 protoxins respectively) were quantified by comparison to the DiPel standard curve using Bio-Rad Quantity One 4.2.3 software.

Insect bioassays. Bioassays were carried out using 4-day-old Trichoplusia ni (cabbage looper), 4-day-old Plutella xylostella (diamondback moth) or 2-day-old Spodoptera exigua (beet armyworm) from laboratory-reared colonies (Valent Biosciences Corporation's quality assurance facility). All bacterial treatments were incorporated into the diet. Two or three replications were included in each study. In each replicate, we tested seven doses of $B$. thuringiensis whole culture and an untreated control. For T. ni and S. exigua, 30 larvae were tested per dose. For P. xylostella, 40 larvae were tested per dose. Insects were incubated at $28 \pm 2{ }^{\circ} \mathrm{C}$ for $T$. $n i$ and $S$. exigua, and at $25 \pm 2{ }^{\circ} \mathrm{C}$ for $P$. xylostella with a $12 \mathrm{~h} \mathrm{light} / 12 \mathrm{~h}$ dark cycle for 3 days. Larval mortality values from all of the replications were pooled and using log-probit analysis, a single regression line was used to estimate the $50 \%$ lethal concentration $\left(\mathrm{LC}_{50}\right)$.

\section{RESULTS}

\section{Detection and sequence analysis of enterotoxin genes in B. thuringiensis VBTS 2477}

The goal of this work was to identify and delete the enterotoxin genes present in a strain of $B$. thuringiensis, and assess the efficacy of the resulting mutant as a bioinsecticide. PCR screening indicated that all 10 enterotoxin genes ( $h b l C, h b l D, h b l A, h b l C_{a}, h b l D_{a}, h b l A_{a}$, nheA, nheB, nheC and $c y t K$ ) were present in strain VBTS 2477 (data not shown). The near full-length $h b l_{a}$ operon from VBTS 2477 has $98 \%$ identity to the $B$. cereus UW85 $h b l_{a}$ operon at the nucleotide level. After $h b l_{a}$ was deleted, a third $h b l D$ homologue was revealed in VBTS 2477. Further analysis showed that this gene was part of a third $h b l$ operon (Fig. 1), which exhibits higher sequence similarity to $h b l_{a}$ than to $h b l$. Therefore, this third set of HBL genes was denoted as $h b l_{a 2}$, and the $h b l_{a}$ detected originally was designated $h b l_{a 1}$. Sequence analyses of the three nearly-fulllength $h b l$ operons in VBTS 2477 show that the $h b l_{a 1}$ and $h b l_{a 2}$ gene sequences are $96-97 \%$ identical and the deduced protein sequences are $97-98 \%$ identical. The $h b l$ genes are 76-84\% identical to $h b l_{a 1}$ and $h b l_{a 2}$ genes, and the deduced proteins are $68-85 \%$ identical. 


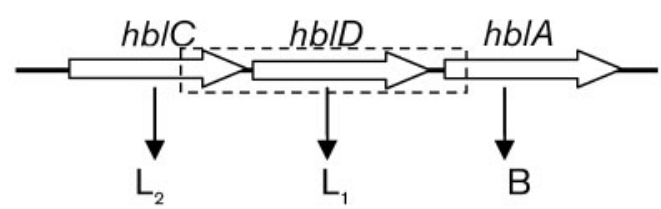

$h b l$

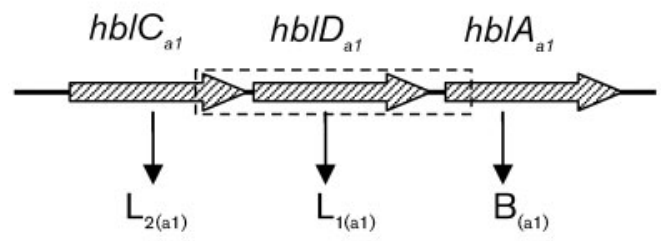

$h b_{a 1}$

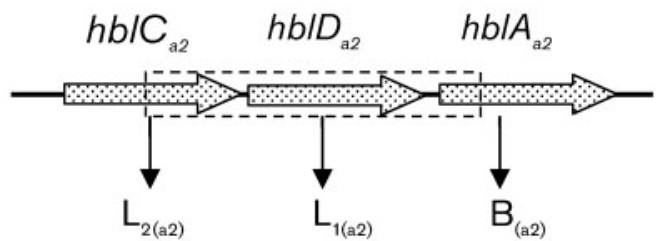

$h b l_{\mathrm{a} 2}$

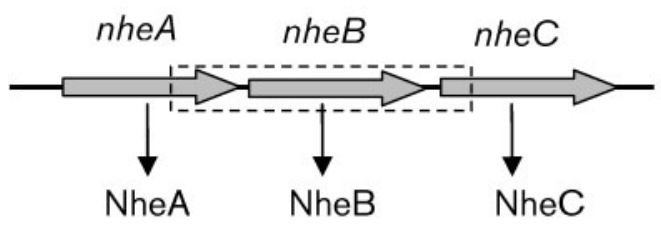

nhe

Fig. 1. $h b /$ and $n$ he operons in B. thuringiensis VBTS 2477. The dotted rectangles indicate the deletion that was introduced into each operon. Vertical arrows indicate the protein product of the gene.

Sequence analysis of the $c y t K$ gene in strain VBTS 2477 revealed that it is the less toxic variant, $c y t K-2$ (Fagerlund et al., 2004). The CytK-2 protein is $89 \%$ identical to CytK1 at the amino acid level and exhibits only about $20 \%$ of the toxicity of CytK-1 toward human intestinal cells (Fagerlund et al., 2004), making its role in virulence uncertain.

\section{Deletion constructs and gene replacement}

SOEing PCR was used to generate deletion constructs of $h b l, h b l_{a 1}, h b l_{a 2}$ and nhe that contained a portion of the first gene spliced to a portion of the last enterotoxin gene of the operon (Supplementary Table S1). The native genes in $B$. thuringiensis VBTS 2477 were successively replaced with the deletion constructs by an iterative process in the order $\Delta h b l_{a 1}, \Delta n h e, \Delta h b l$ and $\Delta h b l_{a 2}$ (Fig. 1 and Fig. 2).

\section{Biological activities of enterotoxin-deficient mutants}

B. thuringiensis strain VBTS 2477, the single mutant $\left(\Delta h b l_{a 1}\right)$ and the double $\left(\Delta h b l_{a 1} \Delta n h e\right)$ mutant each exhibited a strong agglutination response (Table 2) when tested with the Oxoid BCET-RPLA kit, which detects the $\mathrm{L}_{2}$

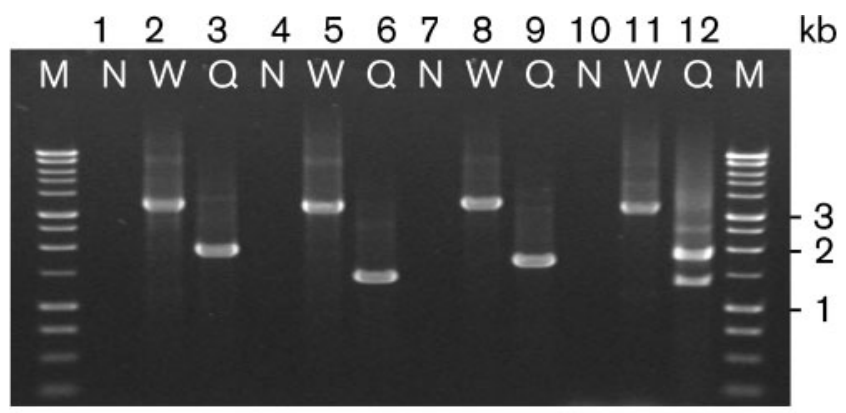

Fig. 2. $P C R$ analysis of $B$. thuringiensis VBTS 2477 and quadruple-enterotoxin-deletion mutant. PCR primers were used to amplify: $h b l_{a 1}$ (lanes $1-3 ;$ hblCa-F/hblAa-R), nhe (4-6; nheA-F/ nheC-R) and (7-9; hblC-F/hblA-R); hbl ${ }_{a 2}$ (10-12; hblCa_Bam-F/ hblAa_Bam-R). M, molecular mass standards (Promega $1 \mathrm{~kb}$ ladder); $\mathrm{N}$, negative control (no DNA); W, wild-type strain; $\mathrm{Q}$, quadruple mutant.

component of HBL (Beecher \& Wong, 1994a). The triple deletion mutant, in which $h b l$ is deleted, exhibited a negative phenotype, indicating that expression of the $\mathrm{L}_{2}$ protein was abolished in this mutant. Since the $h b l_{a 2}$ operon remained intact in the triple mutant, either $\mathrm{L}_{2(\mathrm{a} 2)}$ is not expressed in strain VBTS 2477 or it does not react with the anti- $\mathrm{L}_{2}$ antibody in the RPLA kit. Haemolysis on sheep blood agar suggests that $\mathrm{L}_{2(\mathrm{a} 2)}$ is expressed in VBTS 2477 since the haemolytic activity of the quadruple mutant is diminished compared with the triple mutant (data not shown). Therefore, it is likely that $\mathrm{L}_{2 \mathrm{a}}$ is antigenically distinct from $\mathrm{L}_{2}$. In the Tecra BDE assay, which detects NheA, both the wild-type and the single mutant $\left(\Delta h b l_{a 1}\right)$ exhibited positive reactions (Table 2). The double mutant, in which nhe had been deleted, exhibited a negative reaction, as did the triple and quadruple mutants.

SDS-PAGE analysis indicated that VBTS 2477 and the quadruple mutant produce similar quantities of the

Table 2. Detection of enterotoxins by commercial immunoassays

\begin{tabular}{|llcc|}
\hline Strain & \multicolumn{1}{c|}{ Genotype } & $\begin{array}{c}\text { Oxoid } \\
\text { RPLA }^{*}\end{array}$ & $\begin{array}{c}\text { Tecra } \\
\text { BDE } \dagger\end{array}$ \\
\hline VBTS 2477 & Wild-type & 1024 & 4 \\
AK7701 & $\Delta h b l_{a 1}$ & 1024 & 4 \\
AK7702 & $\Delta h b l_{a 1} \Delta n h e$ & 1024 & 1 \\
AK7703 & $\Delta h b l_{a 1} \Delta n h e \Delta h b l$ & Negative & 1 \\
AK7704 & $\Delta h b l_{a 1} \Delta n h e \Delta h b l \Delta h b l_{a 2}$ & Negative & 1 \\
\hline
\end{tabular}

${ }^{\star}$ RPLA assay results are reported as the reciprocal of the highest dilution (in a series of twofold dilutions) that produced a positive agglutination. Identical results were obtained in two independent experiments. $\dagger \mathrm{BDE}$ assay results are reported according to the manufacturer's instructions where scores of 3,4 or 5 are positive and 1 or 2 are negative. Identical results were obtained in two independent experiments. 
insecticidal crystal protoxins (Table 3). The wild-type and quadruple mutant had similar insecticidal activity against three lepidopteran species: cabbage looper, diamondback moth and beet armyworm (Table 4).

\section{DISCUSSION}

In this study we identified and deleted genes encoding four presumptive enterotoxins in a strain of $B$. thuringiensis. This is the first report, to our knowledge, of a strain of $B$. cereus or $B$. thuringiensis containing three homologues of HBL. This work provides genetic evidence that the enterotoxins are not required for insecticidal activity in the tested species.

We demonstrate that the enterotoxins are characterized by both conservation and heterogeneity. Heterogeneity in the HBL components was first noted by Schoeni \& Wong (1999) in Western blot analyses, which led to the isolation of two distinct sets of HBL components from B. cereus (Beecher \& Wong, 2000). Recently, sequence analysis revealed an $h b l_{a}$ operon in Bacillus weihenstephanensis KBAB4 and B. cereus 03BB108, which also contains the $h b l$ operon (Stenfors Arnesen et al., 2008). The two homologues in strain 03BB108 have $78-82 \%$ identity to each other (Stenfors Arnesen et al., 2008), which is comparable to the similarity observed among the $h b l_{a 1} / h b l_{a 2}$ and $h b l$ homologues in $B$. thuringiensis strain VBTS 2477. Furthermore, the $h b l_{a 1}$ and $h b l_{a 2}$ genes in B. thuringiensis VBTS 2477 are $91-94 \%$ identical to those in B. weihenstephanensis KBAB4 and 84$96 \%$ identical to those in B. cereus 03BB108.

Many strains of B. cereus and B. thuringiensis isolated from diverse origins contain some combination of genes encoding NHE, HBL and CytK (Gaviria Rivera et al., 2000; Hansen \& Hendriksen, 2001; Guinebretière et al., 2002; Ehling-Schulz et al., 2005; Thaenthanee et al., 2005; Ehling-Schulz et al., 2006; Moravek et al., 2006; Swiecicka et al., 2006; Ngamwongsatit et al., 2008). The nhe operon is nearly universal among $B$. cereus and $B$. thuringiensis strains, whereas the $h b l$ operon and $c y t K$ gene are less common. However, past studies may underestimate the prevalence of $\mathrm{hbl}$ homologues because the genes are detected most often by PCR and the primers used would probably not amplify the $h b l_{a}$ variant. Furthermore, the Oxoid RPLA immunoassay did not detect the $\mathrm{L}_{2}$ component of $\mathrm{HBL}_{\mathrm{a} 2}$ in $B$. thuringiensis strain VBTS 2477 , although it is probably expressed; haemolysis activity of the triple mutant, in which $h b l_{a 2}$ is intact, is greater than in the quadruple mutant in which it is deleted. These data suggest that the $\mathrm{L}_{2 \mathrm{a}}$ proteins are antigenically distinct from the prototypic $\mathrm{L}_{2}$ protein. Therefore, the Oxoid kit may be specific for the prototypic $\mathrm{L}_{2}$ protein only. In our work, we found $h b l_{a}$ present in two strains of B. cereus and six strains of B. thuringiensis, including VBTS 2477 (data not shown), suggesting that $h b l_{a}$ is a common variant of the $h b l$ family.

The broad distribution and presence of multiple copies and variants of $\mathrm{HBL}$ in $B$. cereus and $B$. thuringiensis strains suggests that they play an ecological role in the life of the bacterium. Kyei-Poku et al. (2007) showed that the nhe operon and the $h b l A$ gene are expressed in spruce budworm larvae, and therefore speculated that the enterotoxins might have a role in insect pathogenicity. Salamitou et al. (2000) showed that a mutant of $B$. thuringiensis disrupted in the plcR gene, which encodes a regulator of extracellular virulence factors including the enterotoxins, exhibits reduced mortality toward Galleria mellonella, suggesting that genes regulated by plcR contribute to entomopathogenicity in this insect. However, deletion of the nhe and three $h b l$ operons from strain VBTS 2477 did not affect its toxicity to the three lepidopteran pests we tested.

We did not encounter difficulty in introducing a deletion that spanned all three genes of the nhe operon in $B$. thuringiensis VBTS 2477, as has been reported by others (Ramarao \& Lereclus, 2006; Fagerlund et al., 2008; Stenfors Arnesen et al., 2008). However, we did initially have difficulty obtaining deletions in the $h b l$ and $h b l_{a 1}$ operons. We first attempted to construct these mutants by introducing the deletion constructs on a suicide vector that does not replicate in B. thuringiensis. The constructs integrated, but we did not find any double recombinants containing the deletions. In contrast, when we reintroduced the deletion constructs on a temperature-sensitive vector (pMAD), we obtained the $h b l$ and $h b l_{a 1}$ deletion mutants without difficulty; however, $h b l_{a 2}$ presented challenges. We attempted to use pMAD for construction of the $h b l_{a 2}$ deletion mutant as well, and obtained integrants, but only found double recombinants that had reverted to wild-type at a low frequency. In contrast, we obtained the $h b l_{a 2}$ deletion with the pBKJ236/pBKJ223 system. Our work illustrates an

Table 3. Crystal toxin accumulation in culture broths from 7.5 I fermenters

Protein quantified by gel analysis software (Bio-Rad Quantity One 4.1.1) of SDS-PAGE gels stained with Colloidal Blue (Invitrogen). Values represent one replication.

\begin{tabular}{|c|c|c|c|}
\hline \multirow[t]{2}{*}{ Strain } & \multirow[t]{2}{*}{ Protoxin in culture broth $\left(\mathrm{mg} \mathrm{ml}^{-1}\right)$} & \multicolumn{2}{|c|}{ Proportion of crystal toxin as a protoxin of } \\
\hline & & $135 \mathrm{kDa}(\%)$ & $60 \mathrm{kDa}(\%)$ \\
\hline VBTS 2477 & 8.4 & 63 & 37 \\
\hline AK7704, quadruple mutant & 11.6 & 69 & 31 \\
\hline
\end{tabular}


Table 4. Insecticidal activity against lepidopteran larvae

B. thuringiensis culture broths from 7.51 fermenters were fed to 4-day-old T. ni, 2-day-old S. exigua and 4-day-old P. xylostella larvae. Larval mortality was assessed after 3 days. CI, Confidence interval.

\begin{tabular}{|c|c|c|c|}
\hline \multirow[t]{2}{*}{ Strain } & \multicolumn{3}{|c|}{ Insecticidal activity, $\mathrm{LC}_{50}\left[\mu \mathrm{g}\right.$ broth $\left.(\mathrm{ml} \text { diet })^{-1}\right]$ against:* } \\
\hline & T. $n i(95 \% \mathrm{CI})$ & S. exigua $(95 \% \mathrm{CI})$ & P. xylostella $(95 \% \mathrm{CI})$ \\
\hline AK7704, quadruple mutant & $145(131-160)$ & $632(545-730)$ & $11.1(9.91-12.8)$ \\
\hline
\end{tabular}

${ }^{*}$ Values represent the mean of three replicates for T. ni, two replicates for S. exigua and P. xylostella. For each replicate 30 larvae of T. ni and S. exigua, and 40 larvae of $P$. xylostella were tested.

unexplained dimension of the members of the B. cereus group, which have genetic proclivities that defy simple explanations. It is therefore fortuitous that a number of gene-replacement vectors are now available to deal with loci that are recalcitrant to recombination with one.

The potential for spores of a $B$. thuringiensis bioinsecticide to enter the human food supply and cause food poisoning has been a point of debate. The US Environmental Protection Agency states in the 1998 Reregistration Eligibility Decision on Bacillus thuringiensis that enterotoxin levels produced by commercial strains of $B$. thuringiensis are low compared with a clinical isolate of $B$. cereus, and because there are no reports of food poisoning caused by $B$. thuringiensis, it is unlikely to contribute to the prevalence of the diarrhoeal syndrome (US Environmental Protection Agency, 1998; http://www.epa. gov/oppsrrd1/REDs/0247.pdf). Recent studies, however, have shown that levels of enterotoxin production vary among strains of B. cereus and B. thuringiensis (Hansen \& Hendriksen, 2001; Guinebretière et al., 2002; Moravek et al., 2006; Fagerlund et al., 2007), and the pathogenic potential of a particular strain probably results from many factors, including the number of bacterial cells ingested, the number and type of enterotoxins present, the levels of enterotoxin expression, the type of food in which they are ingested, the degree of stomach acidity, the concentration of bile and the composition of the gut microbiota (Clavel et al., 2004, 2007).

The levels of B. thuringiensis recovered from fresh produce range from fewer than 100 c.f.u. $\mathrm{g}^{-1}$ from cabbage products (Hendriksen \& Hansen, 2006) to $>10^{4}$ c.f.u. $\mathrm{g}^{-1}$ on cucumbers and cherry tomatoes (Frederiksen et al., 2006). The infective dose of $B$. cereus diarrhoeal syndrome is $10^{5}-10^{8}$ total cells or spores (Stenfors Arnesen et al., 2008). Frederiksen et al. (2006) postulated that it is therefore conceivable that a human could consume an infective dose from such produce. A recent report analysed B. cereus-group strains isolated from 39 food poisoning outbreaks and determined that in four of the outbreaks only $B$. thuringiensis isolates were recovered from food samples (McIntyre et al., 2008), suggesting that $B$. thuringiensis can be responsible for food poisoning when B. cereus is implicated, because isolates are not routinely examined for the presence of crystal toxin genes or proteins (Granum, 2002; European Food Safety Authority, 2005). Although food poisoning generally, and that caused by $B$. cereus in particular, is vastly underreported, evidence suggests that if $B$. thuringiensis is a cause of food poisoning, it is probably not one of the more common causes. The CDC report 'Surveillance for Foodborne Disease Outbreaks - United States, 2006' indicates that B. cereus accounted for $1 \%$ as a cause of foodborne disease outbreaks, a drop from $2 \%$ for 2001-2005, and few of these were associated with foods derived from crops that are typically treated with $B$. thuringiensis as an insecticide (CDC, 2009).

For many years, $B$. thuringiensis bioinsecticides have been considered safe and effective despite the presence of enterotoxin genes. This work has improved upon this strain of B. thuringiensis subsp. kurstaki by removing any potential for enterotoxin production without negatively affecting the insecticidal activity of the strain. Furthermore, removal of the enterotoxin genes allows for differentiation from other B. thuringiensis and B. cereus strains.

\section{ACKNOWLEDGEMENTS}

We gratefully acknowledge Valent BioSciences Corporation for performing the SDS-PAGE analysis and insect bioassays. We thank S. Stibitz (US FDA, Center for Biologics Evaluation and Research) for providing pBKJ236, pBKJ223 and E. coli strain SS1827. This work was supported by Valent Biosciences, USDA Hatch Grant 4534, and USDA National Research Initiative Competitive Grants Program (NRICGP) no. 98-35316-63312.

\section{REFERENCES}

Agata, N., Ohta, M., Mori, M. \& Isobe, M. (1995). A novel dodecadepsipeptide, cereulide, is an emetic toxin of Bacillus cereus. FEMS Microbiol Lett 129, 17-20.

Arnaud, M., Chastanet, A. \& Débarbouillé, M. (2004). New vector for efficient allelic replacement in naturally nontransformable, low-GCcontent, Gram-positive bacteria. Appl Environ Microbiol 70, 68876891.

Beecher, D. J. \& MacMillan, J. D. (1991). Characterization of the components of hemolysin BL from Bacillus cereus. Infect Immun 59, 1778-1784. 
Beecher, D. J. \& Wong, A. C. (1994a). Identification and analysis of the antigens detected by two commercial Bacillus cereus diarrheal enterotoxin immunoassay kits. Appl Environ Microbiol 60, 46144616.

Beecher, D. J. \& Wong, A. C. (1994b). Improved purification and characterization of hemolysin $\mathrm{BL}$, a hemolytic dermonecrotic vascular permeability factor from Bacillus cereus. Infect Immun 62, 980-986.

Beecher, D. J. \& Wong, A. C. (2000). Tripartite haemolysin BL: isolation and characterization of two distinct homologous sets of components from a single Bacillus cereus isolate. Microbiology 146, $1371-1380$

Beecher, D. J., Pulido, J. S., Barney, N. P. \& Wong, A. C. L. (1995). Extracellular virulence factors in Bacillus cereus endophthalmitis: methods and implication of involvement of hemolysin BL. Infect Immun 63, 632-639.

Bergdoll, M. S. (1988). Ileal loop fluid accumulation test for diarrheal toxins. Methods Enzymol 165, 306-323.

Bizzarri, M. F. \& Bishop, A. H. (2007). Recovery of Bacillus thuringiensis in vegetative form from the phylloplane of clover (Trifolium hybridum) during a growing season. J Invertebr Pathol 94, 38-47.

Carlson, C. R., Caugant, D. A. \& Kolstø, A. B. (1994). Genotypic diversity among Bacillus cereus and Bacillus thuringiensis strains. Appl Environ Microbiol 60, 1719-1725.

CDC (2009). Surveillance for foodborne disease outbreaks - United States, 2006. MMWR 58, 609-615.

Clavel, T., Carlin, F., Lairon, D., Nguyen-The, C. \& Schmitt, P. (2004). Survival of Bacillus cereus spores and vegetative cells in acid media simulating human stomach. J Appl Microbiol 97, 214-219.

Clavel, T., Carlin, F., Daragaignaratz, C., Lairon, D., Nguyen-The, C. \& Schmitt, P. (2007). Effects of porcine bile on survival of Bacillus cereus vegetative cells and Haemolysin $\mathrm{BL}$ enterotoxin production in reconstituted human small intestine media. J Appl Microbiol 103, $1568-1575$.

Damgaard, P. H. (1995). Diarrhoeal enterotoxin production by strains of Bacillus thuringiensis isolated from commercial Bacillus thuringiensis-based insecticides. FEMS Immunol Med Microbiol 12, 245-250.

Ehling-Schulz, M., Svensson, B., Guinebretier, M. H., Lindbäck, T., Andersson, M., Schulz, A., Fricker, M., Christiansson, A., Granum, P. E. $\&$ other authors (2005). Emetic toxin formation of Bacillus cereus is restricted to a single evolutionary lineage of closely related strains. Microbiology 151, 183-197.

Ehling-Schulz, M., Guinebretier, M. H., Monthán, A., Berge, O., Fricker, M. \& Svensson, B. (2006). Toxin gene profiling of enterotoxic and emetic Bacillus cereus. FEMS Microbiol Lett 260, 232-240.

European Food Safety Authority (2005). Opinion of the scientific panel on biological hazards on Bacillus cereus and other Bacillus spp. in foodstuffs. http://www.efsa.europa.eu/cs/BlobServer/Scientific_ Opinion/biohaz_ej175_op_bacillus_enfinal1.pdf?ssbinary=true.

Fagerlund, A., Ween, A., Lund, T., Hardy, S. P. \& Granum, P. E. (2004). Genetic and functional analysis of the $c y t K$ family of genes in Bacillus cereus. Microbiology 150, 2689-2697.

Fagerlund, A., Brillard, J., Fürst, R., Guinebretière, M. H. \& Granum, P. E. (2007). Toxin production in a rare and genetically remote cluster of strains of the Bacillus cereus group. BMC Microbiol 7, 43.

Fagerlund, A., Lindbäck, T., Storset, A. K., Granum, P. E. \& Hardy, S. P. (2008). Bacillus cereus Nhe is a pore-forming toxin with functional properties similar to the ClyA (HlyE, SheA) family of haemolysins, able to induce osmotic lysis in epithelia. Microbiology 154, 693-704.
Fisher, R. \& Rosner, L. (1959). Toxicology of the microbial insecticide, Thuricide. J Agric Food Chem 7, 686-689.

Frederiksen, K., Rosenquist, H., Jørgensen, K. \& Wilcks, A. (2006). Occurrence of natural Bacillus thuringiensis contaminants and residues of Bacillus thuringiensis insecticides on fresh fruits and vegetables. Appl Environ Microbiol 72, 3435-3440.

Gaviria Rivera, A. M., Granum, P. E. \& Priest, F. G. (2000). Common occurrence of enterotoxin genes and enterotoxicity in Bacillus thuringiensis. FEMS Microbiol Lett 190, 151-155.

Granum, P. E. (2002). Bacillus cereus and food poisoning. In Applications and Systematics of Bacillus and Relatives, pp. 37-46. Edited by R. Berkeley, M. Heyndrickx, N. Logan \& P. De Vos. Oxford: Blackwell Science Ltd.

Granum, P. E., O'Sullivan, K. \& Lund, T. (1999). The sequence of the non-haemolytic enterotoxin operon from Bacillus cereus. FEMS Microbiol Lett 177, 225-229.

Guinebretière, M. H., Broussolle, V. \& Nguyen-The, C. (2002). Enterotoxigenic profiles of food-poisoning and food-borne Bacillus cereus strains. J Clin Microbiol 40, 3053-3056.

Hanahan, D. (1983). Studies on transformation of Escherichia coli with plasmids. J Mol Biol 166, 557-580.

Hansen, B. M. \& Hendriksen, N. B. (2001). Detection of enterotoxin Bacillus cereus and Bacillus thuringiensis strains by PCR analysis. Appl Environ Microbiol 67, 185-189.

Hardy, S. P., Lund, T. \& Granum, P. E. (2001). CytK toxin of Bacillus cereus forms pores in planar lipid bilayers and is cytotoxic to intestinal epithelia. FEMS Microbiol Lett 197, 47-51.

Heinrichs, J. H., Beecher, D. J., MacMillan, J. D. \& Zilinskas, B. A. (1993). Molecular cloning and characterization of the hblA gene encoding the $\mathrm{B}$ component of hemolysin $\mathrm{BL}$ from Bacillus cereus. J Bacteriol 175, 6760-6766.

Helgason, E., Økstad, O. A., Caugant, D. A., Johansen, H. A., Fouet, A., Mock, M., Hegna, I. \& Kolstø, A. B. (2000). Bacillus anthracis, Bacillus cereus, and Bacillus thuringiensis - one species on the basis of genetic evidence. Appl Environ Microbiol 66, 2627-2630.

Hendriksen, N. B. \& Hansen, B. M. (2006). Detection of Bacillus thuringiensis kurstaki HD1 on cabbage for human consumption. FEMS Microbiol Lett 257, 106-111.

Hill, K. K., Ticknor, L. O., Okinaka, R. T., Asay, M., Blair, H., Bliss, K. A., Laker, M., Pardington, P. E., Richardson, A. P. \& other authors (2004). Fluorescent amplified fragment length polymorphism analysis of Bacillus anthracis, Bacillus cereus, and Bacillus thuringiensis isolates. Appl Environ Microbiol 70, 1068-1080.

Horton, R. M., Hunt, H. D., Ho, S. N., Pullen, J. K. \& Pease, L. R. (1989). Engineering hybrid genes without the use of restriction enzymes: gene splicing by overlap extension. Gene 77, 61-68.

Janes, B. K. \& Stibitz, S. (2006). Routine markerless gene replacement in Bacillus anthracis. Infect Immun 74, 1949-1953.

Jara, S., Maduell, P. \& Orduz, S. (2006). Diversity of Bacillus thuringiensis strains in maize and bean phylloplane and their respective soils in Colombia. J Appl Microbiol 101, 117-124.

Jensen, G. B., Larsen, P., Jacobsen, B. L., Madsen, B., Smidt, L. \& Andrup, L. (2002). Bacillus thuringiensis in fecal samples from greenhouse workers after exposure to $B$. thuringiensis-based pesticides. Appl Environ Microbiol 68, 4900-4905.

Jensen, G. B., Hansen, B. M., Eilenberg, J. \& Mahillon, J. (2003). The hidden lifestyles of Bacillus cereus and relatives. Environ Microbiol 5, 631-640.

Kotiranta, A., Lounatmaa, K. \& Haapasalo, M. (2000). Epidemiology and pathogenesis of Bacillus cereus infections. Microbes Infect 2, 189198. 
Kyei-Poku, G., Gauthier, D., Pang, A. \& van Frankenhuyzen, K. (2007). Detection of Bacillus cereus virulence factors in commercial products of Bacillus thuringiensis and expression of diarrheal enterotoxins in a target insect. Can J Microbiol 53, 1283-1290.

Lindbäck, T., Fagerlund, A., Rødland, M. S. \& Granum, P. E. (2004). Characterization of the Bacillus cereus Nhe enterotoxin. Microbiology 150, 3959-3967.

Lund, T. \& Granum, P. E. (1996). Characterisation of a nonhaemolytic enterotoxin complex from Bacillus cereus isolated after a foodborne outbreak. FEMS Microbiol Lett 141, 151-156.

Lund, T. \& Granum, P. E. (1997). Comparison of biological effect of the two different enterotoxin complexes isolated from three different strains of Bacillus cereus. Microbiology 143, 3329-3336.

Lund, T., De Buyser, M. L. \& Granum, P. E. (2000). A new cytotoxin from Bacillus cereus that may cause necrotic enteritis. Mol Microbiol 38, 254-261.

Margulis, L., Jorgensen, J. Z., Dolan, S., Kolchinsky, R. \& Rainey, F. A. (1998). The Arthromitus stage of Bacillus cereus: intestinal symbionts of animals. Proc Natl Acad Sci U S A 95, 1236-1241.

Martin, P. A. \& Travers, R. S. (1989). Worldwide abundance and distribution of Bacillus thuringiensis isolates. Appl Environ Microbiol 55, 2437-2442.

McIntyre, L., Bernard, K., Beniac, D., Isaac-Renton, J. L. \& Naseby, D. C. (2008). Identification of Bacillus cereus group species, associated with food poisoning outbreaks in British Columbia, Canada. Appl Environ Microbiol 74, 7451-7453.

Moravek, M., Dietrich, R., Buerk, C., Broussolle, V., Guinebretière, M. H., Granum, P. E., Nguyen-The, C. \& Märtlbauer, E. (2006). Determination of the toxic potential of Bacillus cereus isolates by quantitative enterotoxin analyses. FEMS Microbiol Lett 257, 293-298.

Ngamwongsatit, P., Buasri, W., Pianariyanon, P., Pulsrikarn, C., Ohba, M., Assavanig, A. \& Panbangred, W. (2008). Broad distribution of enterotoxin genes ( $h b l C D A$, nheABC, cytK, and entFM) among Bacillus thuringiensis and Bacillus cereus as shown by novel primers. Int J Food Microbiol 121, 352-356.

Raffel, S. J., Stabb, E. V., Milner, J. L. \& Handelsman, J. (1996). Genotypic and phenotypic analysis of zwittermicin A-producing strains of Bacillus cereus. Microbiology 142, 3425-3436.

Ramarao, N. \& Lereclus, D. (2006). Adhesion and cytotoxicity of Bacillus cereus and Bacillus thuringiensis to epithelial cells are FlhA and PlcR dependent, respectively. Microbes Infect 8, 1483-1491.

Rasko, D. A., Altherr, M. R., Han, C. S. \& Ravel, J. (2005). Genomics of the Bacillus cereus group of organisms. FEMS Microbiol Rev 29, 303 329.
Rosenquist, H., Smidt, L., Andersen, S. R., Jensen, G. B. \& Wilcks, A. (2005). Occurrence and significance of Bacillus cereus and Bacillus thuringiensis in ready-to-eat food. FEMS Microbiol Lett 250, 129136.

Ryan, P. A., MacMillan, J. D. \& Zilinskas, B. A. (1997). Molecular cloning and characterization of the genes encoding the $\mathrm{L}_{1}$ and $\mathrm{L}_{2}$ components of hemolysin BL from Bacillus cereus. J Bacteriol 179, 2551-2556.

Salamitou, S., Ramisse, F., Brehélin, M., Bourguet, D., Gilois, N., Gominet, M., Hernandez, E. \& Lereclus, D. (2000). The plcR regulon is involved in the opportunistic properties of Bacillus thuringiensis and Bacillus cereus in mice and insects. Microbiology 146, 28252832.

Schoeni, J. L. \& Wong, A. C. (1999). Heterogeneity observed in the components of hemolysin BL, an enterotoxin produced by Bacillus cereus. Int J Food Microbiol 53, 159-167.

Silo-Suh, L. A., Lethbridge, B. J., Raffel, S. J., He, H., Clardy, J. \& Handelsman, J. (1994). Biological activities of two fungistatic antibiotics produced by Bacillus cereus UW85. Appl Environ Microbiol 60, 2023-2030.

Smith, R. A. \& Couche, G. A. (1991). The phylloplane as a source of Bacillus thuringiensis variants. Appl Environ Microbiol 57, 311315.

Stenfors Arnesen, L. P., Fagerlund, A. \& Granum, P. E. (2008). From soil to gut: Bacillus cereus and its food poisoning toxins. FEMS Microbiol Rev 32, 579-606.

Swiecicka, I. \& Mahillon, J. (2006). Diversity of commensal Bacillus cereus sensu lato isolated from the common sow bug (Porcellio scaber, Isopoda). FEMS Microbiol Ecol 56, 132-140.

Swiecicka, I., Van der Auwera, G. A. \& Mahillon, J. (2006). Hemolytic and nonhemolytic enterotoxin genes are broadly distributed among Bacillus thuringiensis isolated from wild mammals. Microb Ecol 52, 544-551.

Thaenthanee, S., Wong, A. C. \& Panbangred, W. (2005). Phenotypic and genotypic comparisons reveal a broad distribution and heterogeneity of hemolysin BL genes among Bacillus cereus isolates. Int J Food Microbiol 105, 203-212.

U.S. Environmental Protection Agency (1998). Reregistration Eligibility Decision Document: Bacillus thuringiensis; EPA-738-R98-004; U.S. Environmental Protection Agency, Office of Pesticide Programs, US Government Printing Office: Washington, DC, March 1998. (http://www.epa.gov/oppsrrd1/REDs/0247.pdf)

Edited by: T. Msadek 